\title{
Systemic inflammation associated with mechanical ventilation among extremely preterm infants
}

\author{
Carl L. Bose ${ }^{1}$, Matthew M. Laughon ${ }^{1}$, Elizabeth N. Allred ${ }^{2,3}$, T. Michael O'Shea ${ }^{4}$, Linda J. \\ Van Marter ${ }^{5}$, Richard A. Ehrenkranz ${ }^{6}$, Raina N. Fichorova ${ }^{7}$, Alan Leviton ${ }^{2}$, and ELGAN \\ Study Investigators \\ ${ }^{1}$ Department of Pediatrics, School of Medicine, University of North Carolina, Chapel Hill, NC \\ 27599, USA \\ ${ }^{2}$ Departments of Neurology, Boston Children's Hospital and Harvard Medical School, Boston, MA \\ 02115, USA \\ ${ }^{3}$ Department of Biostatistics, Harvard School of Public Health, Boston, MA 02215, USA \\ ${ }^{4}$ Department of Pediatrics, Wake Forest University School of Medicine, Winston-Salem, NC \\ 27157, USA \\ ${ }^{5}$ Departments of Pediatrics, Brigham and Women's Hospital and Harvard Medical School, \\ Boston, MA 02115, USA \\ ${ }^{6}$ Department of Pediatrics, Yale University School of Medicine, New Haven, CT 06510, USA \\ ${ }^{7}$ Departments of Obstetrics, Gynecology and Reproductive Biology, and Harvard Medical School, \\ Boston, MA 02115, USA
}

\section{Abstract}

Little evidence is available to document that mechanical ventilation is an antecedent of systemic inflammation in preterm humans. We obtained blood on postnatal day 14 from 726 infants born before the 28th week of gestation and measured the concentrations of 25 inflammation-related proteins. We created multivariable models to assess the relationship between duration of ventilation and protein concentrations in the top quartile. Compared to newborns ventilated for fewer than 7 days $(\mathrm{N}=247)$, those ventilated for 14 days $(\mathrm{N}=330)$ were more likely to have elevated blood concentrations of pro-inflammatory cytokines (IL-1 $\beta$, TNF-a), chemokines (IL-8, MCP-1), an adhesion molecule (ICAM-1), and a matrix metalloprotease (MMP-9), and less likely to have elevated blood concentrations of two chemokines (RANTES, MIP-1 $\beta$ ), a matrix metalloproteinase (MMP-1), and a growth factor (VEGF). Newborns ventilated for 7-13 days $(\mathrm{N}=149)$ had systemic inflammation that approximated the pattern of newborns ventilated for 14 days. These relationships were not confounded by chorioamnionitis or antenatal corticosteroid exposure, and were not altered appreciably among infants with and without bacteremia. These findings suggest that two weeks of ventilation are more likely than shorter durations of ventilation

(C) 2012 Elsevier Ltd. All rights reserved.

Corresponding author: Carl Bose, CB\# 7595, UNC Hospitals, Chapel Hill, NC 27599-7596, cbose@ med.unc.edu, telephone: 919-966-6063, fax: 919-966-3034.

Publisher's Disclaimer: This is a PDF file of an unedited manuscript that has been accepted for publication. As a service to our customers we are providing this early version of the manuscript. The manuscript will undergo copyediting, typesetting, and review of the resulting proof before it is published in its final citable form. Please note that during the production process errors may be discovered which could affect the content, and all legal disclaimers that apply to the journal pertain.

Competing Interests

The authors have no conflicts of interest. 
to be accompanied by high blood concentrations of pro-inflammatory proteins indicative of systemic inflammation, and by low concentrations of proteins that might protect from inflammation-mediated organ injury.

\section{Keywords}

inflammation; ventilation; preterm infant; cytokine; chemokine

\section{INTRODUCTION}

Postnatal systemic inflammation in the very preterm newborn is followed by increased risks of lung [1], and brain disorders [2-4]. To minimize such undesirable consequences of systemic inflammation, we consider it prudent to search for the antecedents of systemic inflammation. To date, we have documented that bacteremia is followed/accompanied by systemic inflammation [5]. We now consider another potential postnatal stimulus for systemic inflammation, mechanical ventilation.

In adult animals, mechanical ventilation leads to systemic inflammation [6]. In adult humans, mechanical ventilation is accompanied by a systemic inflammatory response, which is modified by strategies that minimize ventilator-induced lung injury, suggesting a cause and effect relationship between lung inflammation and systemic inflammation [7].

In late preterm and term infants, brief periods of ventilation are accompanied by systemic inflammation [8]. The studies of very preterm newborns, which have also documented systemic inflammation associated with ventilation, have been limited in the number of subjects and the number of indicators of inflammation [9-13].

In order to explore the relationship between the duration of ventilation and systemic inflammation during the first two weeks after birth, we studied 726 infants born before the 28th week of gestation for whom we had information about placenta histology, about ventilation on each of the first 14 days, and about levels of the blood concentrations of 25 inflammation-related proteins on postnatal day 14.

\section{METHODS}

\subsection{Sample Description}

This study is a secondary analysis of data from the ELGAN Study [14]. The ELGAN Study was designed to identify characteristics and exposures that increase the risk of neurologic disorders in ELGANs delivered before 28 weeks gestation. The infants enrolled in this study were born between April 2002 and August 2004. A full description of the methods of the ELGAN Study is provided elsewhere [14], including the enrollment and consent processes that were approved by the individual institutional review boards. Here we focus on those most relevant to this report. Because of financial constraints, the ELGAN Study measured proteins only on infants who had a developmental evaluation at 24 months adjusted age. Measurements were made on blood specimens obtained on or close to postnatal days 1, 7, and 14 .

\subsection{Placenta Morphology}

Samples were collected from placentas for histologic examination, and were processed for morphologic assessment as part of routine clinical care. Details describing the criteria for each histologic lesion are presented elsewhere [15]. In our analyses, placenta inflammation was defined as any of the following four lesions: a) chorionic plate inflammation of grade 3 
(neutrophils up to amnionic epithelium) and stage 3 (>20 neutrophils/20x), b) external membrane inflammation of grade 3 (numerous large or confluent foci of neutrophils), c) umbilical cord inflammation of grade 3 or higher (neutrophils in perivascular Wharton's jelly), and d) neutrophilic infiltration into fetal stem vessels in the chorionic plate.

\subsection{Obstetric and Newborn Variables}

Gestational age estimates were based on a hierarchy of available information, including in declining order, dates of embryo retrieval or intrauterine insemination or fetal ultrasound before the $14^{\text {th }}$ week (62\%), fetal ultrasound at 14 or more weeks $(29 \%)$, last menstrual period without fetal ultrasound (7\%), and gestational age recorded in the log of the neonatal intensive care unit $(1 \%)$. Antenatal corticosteroids were considered complete if the mother received 2 doses of betamethasone or 4 doses of dexamethasone over 48 hours and the last dose was 24 hours before delivery, and were considered partial if ACS treatment was begun but not completed. The birth weight Z-score was calculated using a standard data set [16]. Infants were classified as having a patent ductus arteriosus (PDA) if the diagnosis was assigned by the clinician, on the basis of signs and symptoms or by echocardiography, at any time during the first 2 postnatal weeks.

We classified infants by the number of cumulative days they received mechanical ventilation (either high-frequency or conventional mechanical ventilation) during the first 14 postnatal days. We collected detailed, daily information during the first postnatal week about respiratory support, but for the second week, we recorded the number of days ventilated only. Thus, we limited our analyses to the measure of days of ventilation.

\subsection{Blood Collection and Protein Measurement}

Drops of blood were collected on filter paper (Schleicher \& Schuell 903) on the first postnatal day (range: 1-3 days), the $7^{\text {th }}$ postnatal day (range: 5-8 days), and the $14^{\text {th }}$ postnatal day (range: 12-15 days). Details about elution of proteins from blood spots and measurement of the proteins with an electrochemiluminescence system are provided elsewhere [17].

The Laboratory of Genital Tract Biology of the Department of Obstetrics, Gynecology and Reproductive Biology at Brigham and Women's Hospital, Boston measured the following 25 proteins: IL-1 $\beta$ (interleukin-1beta), IL-6 (interleukin-6), IL-6R (interleukin-6 receptor), TNF-a (tumor necrosis factor-alpha), TNF-R1 (tumor necrosis factor-alpha-receptor1), TNF-R2 (tumor necrosis factor-alpha-receptor2), IL-8 (CXCL8) (interleukin-8), MCP-1 (CCL2) (monocyte chemotactic protein-1), MCP-4 (CCL13) (monocyte chemotactic protein-4) (CCL13), MIP-1 $\beta$ (CCL4) (macrophage inflammatory protein-1 $\beta$ ) (CCL4), RANTES (CCL5) (regulated upon activation, normal T-cell expressed, and [presumably] secreted), I-TAC ( CXCL11) (interferon-inducible T cell alpha-chemoattractant), ICAM-1 (CD54) (intercellular adhesion molecule-1), ICAM-3 (CD50) (intercellular adhesion molecule-3), VCAM-1 (CD106) (vascular cell adhesion molecule-1), E-SEL (CD62E) (Eselectin) (CD62E), MMP-1 (matrix metalloproteinase-1), MMP-9 (matrix metalloproteinase-9), CRP (c-reactive protein), SAA (serum amyloid A), MPO (myeloperoxidase), VEGF (vascular endothelial growth factor), VEGF-R1 (vascular endothelial growth factor-receptor1), VEGF-R2 (vascular endothelial growth factorreceptor2), and IGFBP-1 (insulin growth factor binding protein-1).

Measurements of each protein were normalized to $\mathrm{mg}$ total protein. A protein concentration was classified in the top quartile in comparison to the concentrations of all other concentrations of that protein on that day among all the other infants in the same gestational age group. 


\subsection{Data Analysis}

We evaluated the generalized null hypothesis that blood protein concentrations in the highest quartile for gestational age (23-34, 25-26, and 27 weeks) on day 14 are not associated with the length of ventilation during the first 14 postnatal days. We first created multivariable logistic regression models of the risk of a day-14 protein concentration in the top quartile that compared infants ventilated for 7-13 days and infants ventilated for 14 days to the referent group of infants who were ventilated for less than 7 days and adjusted for the three most important potential confounders, gestational age, placental inflammation, and antenatal corticosteroids. Because bacteremia might be in the causal chain, we did not adjust for postnatal bacteremia. Rather, we repeated our multivariable analyses in the sub-sample of newborns who did not have documented bacteremia during the first two postnatal weeks. We calculated the $99 \%$ confidence intervals rather than the conventional $95 \%$ confidence interval because we wanted to minimize both type 1 and type 2 errors in light of multiple comparisons.

To inform our understanding about the temporal relationship between ventilation and systemic inflammation, we evaluated the hypothesis that systemic inflammation precedes prolonged ventilation by comparing the median (and the 25th and 75th centiles) of ICAM-1, TNF-a, IL-8, and CRP on early blood collection days (postnatal Days 1, and 7) among newborns classified by gestational age group and duration of ventilation.

\section{RESULTS}

\subsection{Cohort Description (Figure 1 and Table 1)}

The cohort for this study included 726 infants. Fully $95 \%$ of these newborns received ventilation assistance at some time in the early part of their NICU stay and $8 \%$ were ventilator dependent during the 36th post-menstrual week. During the first 14 postnatal days, $34 \%$ were ventilated for less than 7 days, $21 \%$ were ventilated for $7-13$ days, and $45 \%$ were ventilated for 14 days. Longer duration of ventilation was more common among infants with low gestational age, low birth weight, low birth weight Z-score, PDA, and receipt of surfactant and postnatal steroid compared to infants without these features (Table $1)$.

\subsection{Distribution of Protein Concentrations (Figure 2)}

Although our emphasis is on the highest quartile of concentrations of each inflammationrelated protein, the entire distribution of some protein concentrations was shifted upward with each week of ventilation during the first two postnatal weeks. These proteins included TNF-a, IL-8, MCP-1 and ICAM-1. By contrast, the entire distributions of RANTES and MMP-1 were shifted downward with each week of ventilation. The distributions of concentrations of SAA and CRP follow neither of these patterns.

When analyses were within strata defined by gestational age and duration of ventilation, infants ventilated 14 days did not tend to have higher protein concentrations on postnatal days 1 and 7 than their peers not ventilated on day 14 (data not shown).

\subsection{Relationship between Duration of Mechanical Ventilation and Protein Concentrations (Table 2)}

After adjustment for gestational age, placental inflammation, and antenatal corticosteroids, compared to infants who were ventilated for less than 7 days, infants who were ventilated for 7-13 days during the first two postnatal weeks were more likely to have elevated concentrations of CRP, SAA, TNF-a, IL-8, ICAM-1, and MMP-9 (data column 1), and less likely to have an elevated concentration of RANTES. Infants ventilated every day during the 
first two weeks were more likely than those who were ventilated for less than 7 days to have elevated concentrations of IL-1 $\beta$, IL-6, TNF- $a$, TNF-R1, IL-8, MCP-1, ICAM-1, and MMP-9 (data column 2) and less likely to have elevated concentrations of MIP-1 $\beta$, RANTES, I-TAC, MMP-1, and VEGF.

Similar multivariable models were also created for the sample of the 597 children who did not have documented bacteremia during the first two postnatal weeks. This set of analyses provided rather similar findings. For example, the elevated odds ratios for SAA, IL-8, and ICAM-1, remained statistically significant for newborns who were ventilated 7-13 days (data column 3). The point estimate of the odds ratio for MMP-9 remained the same, but the $99 \%$ confidence interval widened to include 1.0 .

For the bacteremia-free newborns who were ventilated for 14 days, the odds ratios for IL-6, TNF-a, TNF-R1, IL-8, MCP-1, ICAM-1, and MMP-9 remained statistically significantly elevated, while the odds ratios for MIP-1 $\beta$, RANTES, and MMP-1 remained statistically significantly below 1.0. Point estimates of the odds ratios for IL-1 $\beta$, I-TAC, and VEGF remained the same as in the entire sample, but the confidence intervals were sufficiently widened in this smaller sample that they were no longer statistically significant.

\section{DISCUSSION}

Among a large cohort of ELGANs, we found that the longer infants are ventilated during the first 2 weeks following birth, the more likely they are to have elevated blood concentrations of specific inflammation-related proteins, including pro-inflammatory cytokines, chemokines, an adhesion molecule and a matrix metalloprotease, and decreased concentrations of other proteins that have suspected protective and immunotrophic roles. The pro-inflammatory response is similar to that observed in term and near term infants in whom even brief periods of ventilation are associated with a systemic inflammatory response [8]. Collectively, these observations suggest that systemic inflammation, which might begin soon after the initiation of mechanical ventilation of preterm infants, escalates during the first 2 postnatal weeks with continued exposure to ventilation.

\section{1. possible explanations for what was found}

Our finding that those ventilated the longest were most likely to have systemic inflammation on postnatal day 14 can be interpreted in several ways. One explanation is that ventilation causes lung inflammation, and selected inflammation-associated proteins then translocate from the lung to the circulation. Under these circumstances, concentrations of these proteins might increase with duration of ventilation. Circulating pro-inflammatory proteins might then elicit a downstream response from other organs. For example, this might explain the origin of proteins from the liver (e.g., SAA or CRP). Support for this possible cascade of events comes from the observation that strategies that reduce ventilator-induced lung injury appear to reduce systemic inflammation in both adults [6] and neonates [9].

Another interpretation is that systemic inflammation causes lung inflammation and thereafter the need for prolonged ventilation. Under these circumstances, one would expect infants requiring 14 days of ventilation to have higher early blood concentrations of proinflammatory cytokines than infants who were exposed to ventilation for shorter times. Although the concentrations of some inflammation-associated proteins increased from day 1 to day 7 to day 14 , infants ventilated the longest did not tend to have appreciably higher protein concentrations on postnatal days 1 and 7 . Thus, our data support the hypothesis that "prolonged" ventilation contributes to systemic inflammation rather than the reverse, at least during the first 14 postnatal days. After this early time span, systemic inflammation might very well contribute to the need for prolonged ventilation [18]. 
We also explored the possibility that a specific cause of systemic inflammation, bacteremia, contributed to an increased risk of prolonged ventilation. Support for that possibility comes from the observation that bacteremic preterm newborns require more ventilation assistance than their non-bacteremic peers [19]. With or without a cause and effect relationship, bacteremia can obscure the relationship between ventilation duration and systemic inflammation. To minimize such confounding, we carried out separate analyses in the entire sample and in the sub-sample of newborns who did not have bacteremia documented during the first two postnatal weeks. We found that even in this bacteremia-free group of children, ventilation duration was strongly associated with elevated concentrations of inflammationassociated proteins. Thus, we draw the inference that our findings are not confounded by bacteremia.

The findings of our study might explain, in part, why prolonged ventilation appears to increase the risks of bronchopulmonary dysplasia [20], cerebral palsy [21], and cognitive limitations [22-24]. These findings support the hypothesis that mechanical ventilation initiates or potentiates systemic inflammation in premature infants, which then leads to organ damage and adverse outcomes.

\section{2. potential confounders}

We examined antenatal events that might increase (e.g. chorioamnionitis) or decrease (e.g. antenatal corticosteroids) inflammatory protein concentrations during the early neonatal period. The presence of chorioamnionitis had a negligible effect on the association between duration of ventilation and protein concentrations. One explanation for this finding is that the fetus might down-regulate inflammation and modulate the effects of chronic inflammatory stimuli [25].

Fetal exposure to antenatal corticosteroids might be expected to decrease the systemic inflammatory response in ELGANs. However, antenatal corticosteroids did not modify the relationship between duration of ventilation and inflammation-associated proteins in our cohort. This finding is similar to observations in the premature lamb, where antenatal treatment with betamethasone decreases subsequent lung injury but not the systemic acute phase response [26]. In contrast, pretreatment of adult animals with corticosteroids attenuates both pulmonary and systemic inflammation caused by mechanical ventilation [27].

\subsection{CRP and SAA}

CRP and SAA are the only proteins whose day- 14 concentrations tended to be significantly higher among those ventilated for 7-13 days, but not among those ventilated for 14 days. Unlike the other proteins we measured, these acute phase response are synthesized mainly by hepatocytes. It is possible that their origin outside the lung influences the timing of their appearance in blood. It is also possible that levels are modulated by factors unrelated to ventilation. In the absence of knowledge about these influences in ELGANs, we are unable to provide an explanation for why CRP and SAA differ from other proteins.

\subsection{RANTES and VEGF}

Longer duration of ventilation was accompanied by a decreased risk of elevated concentrations of the chemokine RANTES. This finding might appear to be inconsistent with the expectation of increased concentrations of other chemokines following a stimulus that promotes inflammation. However, this finding is in keeping with observations that RANTES appears to protect against organ damage in some animal models [28, 29], and our observation that human preterm newborns who had elevated blood concentrations of 
RANTES during the first postnatal weeks were at reduced risk of bronchopulmonary dysplasia [1].

Our finding of an inverse relationship between ventilation duration and high concentrations of VEGF is what would be expected if ventilation, in part via reduced VEGF concentrations, impaired lung angiogenesis. For example, levels of VEGF are decreased in the lung epithelial fluid from infants who develop bronchopulmonary dysplasia [30], and a paucity of pulmonary capillaries is seen in animal models of mild bronchopulmonary dysplasia [31]. In addition, ventilation appears to down-regulate gene expression of VEGF-B and other traditional angiogenic factors in extremely preterm infants who die [32].

\section{Strengths and limitations}

This study has a number of strengths and limitations. Our large sample size permitted us to adjust for potential risk modifiers and confounders with sufficient statistical power. We measured a relatively large number of proteins. Our study was confined to infants in a narrow gestational age range. However, it is in this population that prolonged mechanical ventilation is most likely, and the consequences of systemic inflammation are most profound.

Because of financial constraints, blood protein measurements were limited to infants who had complete neurodevelopmental evaluation at 24 months. This resulted in the non-random exclusion of one potentially important cohort, infants who did not survive to 24 months. Among non-survivors, 119 died during the first postnatal week and an additional 165 died prior to discharge. These infants were probably more likely than survivors to have been ventilated and to have had systemic inflammation. Consequently, our requiring survival to age 2 years probably resulted in an underestimate of the true relationship between ventilation and systemic inflammation. Although potentially of less importance, infants who survived but did not return for development testing $(n=98)$ were also excluded. We are uncertain of the impact of these exclusions.

We do not know how much more frequently newborns who were ventilated for 14 days had unidentified pneumonia compared to newborns who were ventilated for shorter intervals [33]. Because of the limitations imposed by our data collection, we also lack details about potential important variables of ventilation (e.g. tidal volumes, oxygen concentrations, etc.), which might influence the inflammatory process. Information regarding these variables would have permitted a more detailed analysis of the antecedents of systemic inflammation.

We conclude that 14 days of ventilation is more likely than shorter durations of ventilation to be accompanied by high blood concentrations of a variety of pro-inflammatory proteins capable of damaging organs, and low concentrations of proteins that might protect from inflammation-mediated organ injury. These associations do not appear to be influenced by chorioamnionitis or exposure to antenatal corticosteroids. These findings have important implications for both providers and researchers. If the systemic inflammation associated with mechanical ventilation originates in the inflamed lung, then avoiding ventilation, or ventilating infants in a manner that reduces lung inflammation, might minimize some of the adverse consequences of systemic inflammation. Perhaps one of the criteria for deciding among ventilation strategies should be their effects on blood concentrations of selected proteins.

\section{Supplementary Material}

Refer to Web version on PubMed Central for supplementary material. 


\section{Acknowledgments}

The authors gratefully acknowledge the contributions of their subjects, and their subjects' families, as well as the following ELGAN Study colleagues for all their contributions:

Bhavesh L. Shah, Baystate Medical Center, Springfield MA; Camilia Martin, Beth Israel Deaconess Medical Center, Boston MA; Linda Van Marter, Brigham \& Women's Hospital, Boston MA; Robert Insoft, Massachusetts General Hospital, Boston, MA; Karl Kuban, Boston Medical Center, Boston, MA; Francis Bednarek, U Mass Memorial Health Center, Worcester, MA; Olaf Dammann, John Fiascone, Cynthia Cole, Tufts Medical Center, Boston MA; Richard A. Ehrenkranz, Yale-New Haven Children's Hospital, New Haven CT; T. Michael O'Shea, Wake Forest University/Baptist Medical Center, Winston-Salem NC; Stephen C. Engelke, University Health Systems of Eastern Carolina, Greenville NC; Carl Bose, University of North Carolina, Chapel Hill NC; Mariel Poortenga, DeVos Children's Hospital, Grand Rapids MI; Padima Karna, Sparrow Hospital, Lansing MI; Nigel Paneth, Michigan State University, East Lansing MI; MichaelD. Schreiber, University of Chicago Hospital, Chicago IL; Daniel Batton, William Beaumont Hospital, Royal Oak MI; Greg Pavlov, Frontier Science and Technology Research Foundation, Amherst, NY, and project officer, Deborah Hirtz

\section{Financial Support}

This study was supported by a cooperative agreement with The National Institute of Neurological Disorders and Stroke (NINDS; 5U01NS040069-05), and a center grant award from the National Institute of Child Health and Human Development (5P30HD018655-28). Dr. Bose was partially supported by the Thrasher Research Fund.

\section{REFERENCES}

[1]. Bose C, Laughon M, Allred EN, Van Marter LJ, O'Shea TM, Ehrenkranz RA, Fichorova RN, Leviton A, Investigators ftES. Blood protein concentrations in the first two postnatal weeks that predict bronchopulmonary dysplasia among infants born before the 28 th week of gestation. Pediatr Research. 12011; 69:347-353.

[2]. Leviton A, Kuban K, O’Shea TM, Paneth N, Fichorova R, Allred EN, Dammann O. The Relationship between Early Concentrations of 25 Blood Proteins and Cerebral White Matter Injury in Preterm Newborns: The ELGAN Study. J Pediatr. 12011; 158:897-903. [PubMed: 21238986]

[3]. Leviton A, Kuban K, Allred EN, Fichorova R, O'Shea TM, Paneth N. Elevated concentrations of circulating indicators of inflammation in infants born before the 28th post-menstrual week predict a small head circumference two years later. Early Hum Dev. 12011; 87:325-330. [PubMed: 21334149]

[4]. O'Shea TM, Allred EN, Kuban K, Dammann O, Paneth N, Fichorova R, Hirtz D, Leviton A, Investigators FtES. Elevated concentrations of inflammation-related proteins in postnatal blood predict severe developmental delay at two years in extremely premature infants. J Pediatr. 12012; 160:395-401.e4.

[5]. Leviton A, O'Shea TM, Bednarek FJ, Allred EN, Fichorova RN, Dammann O. Systemic responses of preterm newborns with presumed or documented bacteraemia. Acta Paediatr. 12012; 101:3559. [PubMed: 22085230]

[6]. Walker MG, Yao LJ, Patterson EK, Joseph MG, Cepinskas G, Veldhuizen RA, Lewis JF, Yamashita CM. The effect of tidal volume on systemic inflammation in Acid-induced lung injury. Respiration. 12011; 81:333-42. [PubMed: 21311175]

[7]. Ranieri VM, Suter PM, Tortorella C, De Tullio R, Dayer JM, Brienza A, Bruno F, Slutsky AS. Effect of mechanical ventilation on inflammatory mediators in patients with acute respiratory distress syndrome: a randomized controlled trial. JAMA. 11999; 282:54-61. [PubMed: 10404912]

[8]. Bohrer B, Silveira RC, Neto EC, Procianoy RS. Mechanical ventilation of newborns infant changes in plasma pro- and anti-inflammatory cytokines. J Pediatr. 12010; 156:16-9. [PubMed: 19783005]

[9]. Capoluongo E, Vento G, Santonocito C, Matassa PG, Vaccarella C, Giardina B, Romagnoli C, Zuppi C, Ameglio F. Comparison of serum levels of seven cytokines in premature newborns undergoing different ventilatory procedures: high frequency oscillatory ventilation or 
synchronized intermittent mandatory ventilation. Eur Cytokine Netw. 12005; 16:199-205. [PubMed: 16266860]

[10]. Turunen R, Nupponen I, Siitonen S, Repo H, Andersson S. Onset of mechanical ventilation is associated with rapid activation of circulating phagocytes in preterm infants. Pediatrics. 12006; 117:448-54. [PubMed: 16452365]

[11]. Turunen R, Vaarala O, Nupponen I, Kajantie E, Siitonen S, Lano A, Repo H, Andersson S. Activation of T cells in preterm infants with respiratory distress syndrome. Neonatology. 12009; 96:248-58. [PubMed: 19468239]

[12]. Turunen R, Andersson S, Laivuori H, Kajantie E, Siitonen S, Repo H, Nupponen I. Increased postnatal inflammation in mechanically ventilated preterm infants born to mothers with earlyonset preeclampsia. Neonatology. 12011; 100:241-7. [PubMed: 21701213]

[13]. Sarafidis K, Stathopoulou T, Agakidou E, Taparkou A, Soubasi V, Diamanti E, Drossou V. Comparable effect of conventional ventilation versus early high-frequency oscillation on serum CC16 and IL-6 levels in preterm neonates. J Perinatol. 12011; 31:104-11. [PubMed: 20671716]

[14]. O'Shea TM, Allred EN, Dammann O, Hirtz D, Kuban KC, Paneth N, Leviton A. The ELGAN study of the brain and related disorders in extremely low gestational age newborns. Early Hum Dev. 12009; 85:719-25.

[15]. Hecht JL, Allred EN, Kliman HJ, Zambrano E, Doss BJ, Husain A, Pflueger SM, Chang CH, Livasy CA, Roberts D, Bhan I, Ross DW, Senagore PK, Leviton A, Investigators ES.

Histological characteristics of singleton placentas delivered before the 28th week of gestation. Pathology. 12008; 40:372-6. [PubMed: 18446627]

[16]. Yudkin PL, Aboualfa M, Eyre JA, Redman CW, Wilkinson AR. New birthweight and head circumference centiles for gestational ages 24 to 42 weeks. Early Hum Dev. 11987; 15:45-52. [PubMed: 3816638]

[17]. Leviton A, Fichorova R, Yamamoto Y, Allred EN, Dammann O, Hecht J, Kuban K, McElrath T, O'Shea TM, Paneth N. Inflammation-related proteins in the blood of extremely low gestational age newborns. The contribution of inflammation to the appearance of developmental regulation. Cytokine. 12011; 53:66-73. [PubMed: 20934883]

[18]. Viscardi RM. Perinatal inflammation and lung injury. Semin Fetal Neonatal Med. 12012; 17:305. [PubMed: 21855435]

[19]. Maayan-Metzger A, Linder N, Marom D, Vishne T, Ashkenazi S, Sirota L. Clinical and laboratory impact of coagulase-negative staphylococci bacteremia in preterm infants. Acta Paediatr. 12000; 89:690-3. [PubMed: 10914964]

[20]. Laughon M, Bose C, Allred EN, O’Shea TM, Ehrenkranz RA, Van Marter LJ, Leviton A, Investigators. ftES. Antecedents of chronic lung disease following three patterns of early respiratory disease in preterm infants. Arch Dis Child Fetal Neonatal Ed. 12011; 96:F114-20. [PubMed: 20688867]

[21]. Van Marter LJ, Kuban KCK, Allred EN, Bose C, Dammann O, O’Shea TM, Laughon M, Ehrenkranz RA, Karna P, Leviton A, Investigators ftES. Does Bronchopulmonary Dysplasia Contribute to the Occurrence of Cerebral Palsy Among Infants Born Before 28 weeks of Gestation? Arch Dis Child Fetal Neonatal Ed. 12011; 96:F20-F29. [PubMed: 20736416]

[22]. Short EJ, Kirchner HL, Asaad GR, Fulton SE, Lewis BA, Klein N, Eisengart S, Baley J, Kercsmar C, Min MO, Singer LT. Developmental sequelae in preterm infants having a diagnosis of bronchopulmonary dysplasia: analysis using a severity-based classification system. Arch Pediatr Adolesc Med. 12007; 161:1082-7. [PubMed: 17984411]

[23]. Laughon M, O’Shea MT, Allred EN, Bose C, Kuban K, Van Marter LJ, Ehrenkranz RA, Leviton A. Chronic lung disease and developmental delay at 2 years of age in children born before 28 weeks' gestation. Pediatrics. 12009; 124:637-48. [PubMed: 19620203]

[24]. Walsh MC, Morris BH, Wrage LA, Vohr BR, Poole WK, Tyson JE, Wright LL, Ehrenkranz RA, Stoll BJ, Fanaroff AA. Extremely low birthweight neonates with protracted ventilation: mortality and 18-month neurodevelopmental outcomes. J Pediatr. 12005; 146:798-804. [PubMed: 15973322]

[25]. Kramer BW, Ikegami M, Jobe AH. Intratracheal endotoxin causes systemic inflammation in ventilated preterm lambs. Am J Respir Crit Care Med. 12002; 165:463-9. [PubMed: 11850337] 
[26]. Hillman NH, Pillow JJ, Ball MK, Polglase GR, Kallapur SG, Jobe AH. Antenatal and postnatal corticosteroid and resuscitation induced lung injury in preterm sheep. Respir Res. 12009; 10:124. [PubMed: 20003512]

[27]. Nin N, Penuelas O, de Paula M, Lorente JA, Fernandez-Segoviano P, Esteban A. Ventilationinduced lung injury in rats is associated with organ injury and systemic inflammation that is attenuated by dexamethasone. Crit Care Med. 12006; 34:1093-8. [PubMed: 16484900]

[28]. Shahrara S, Proudfoot AE, Woods JM, Ruth JH, Amin MA, Park CC, Haas CS, Pope RM, Haines GK, Zha YY, Koch AE. Amelioration of rat adjuvant-induced arthritis by Met-RANTES. Arthritis Rheum. 12005; 52:1907-19. [PubMed: 15934086]

[29]. Dobaczewski M, Xia Y, Bujak M, Gonzalez-Quesada C, Frangogiannis NG. CCR5 signaling suppresses inflammation and reduces adverse remodeling of the infarcted heart, mediating recruitment of regulatory T cells. Am J Pathol. 12010; 176:2177-87. [PubMed: 20382703]

[30]. Lassus P, Ristimaki A, Ylikorkala O, Viinikka L, Andersson S. Vascular endothelial growth factor in human preterm lung. Am J Respir Crit Care Med. 11999; 159:1429-33. [PubMed: 10228106]

[31]. Coalson JJ. Pathology of new bronchopulmonary dysplasia. Semin Neonatol. 12003; 8:73-81. [PubMed: 12667832]

[32]. De Paepe ME, Greco D, Mao Q. Angiogenesis-related gene expression profiling in ventilated preterm human lungs. Exp Lung Res. 12010; 36:399-410. [PubMed: 20718599]

[33]. Garland JS. Strategies to prevent ventilator-associated pneumonia in neonates. Clin Perinatol. 12010; 37:629-43. [PubMed: 20813275] 
- In adults and term infants, ventilation can lead to systemic inflammation.

- Systemic inflammation is associated with short-term ventilation in preterm infants.

- We examined systemic inflammation and duration of ventilation in preterm infants.

- Inflammation was more evident in infants ventilated for 2 weeks than for $<1$ week.

- Longer duration of ventilation may promote systemic inflammation in preterm infants. 


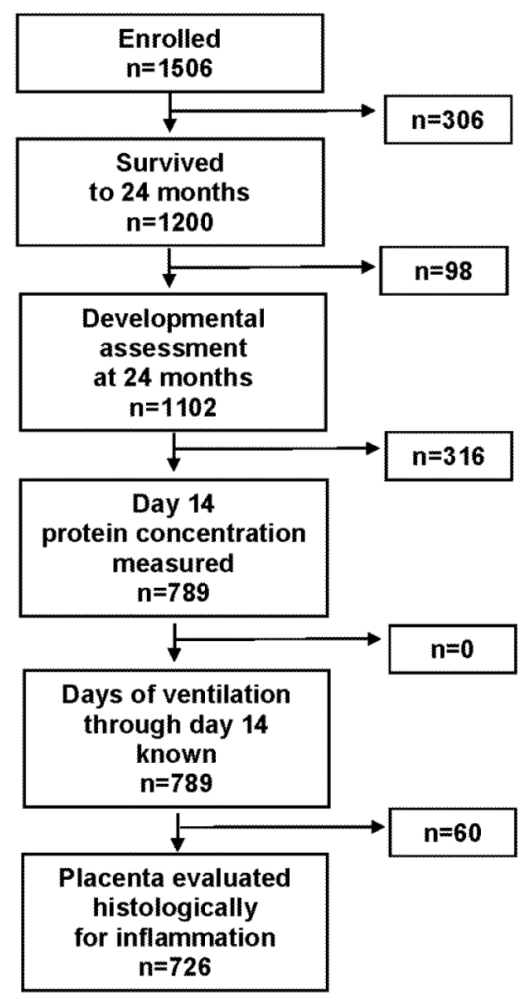

Figure 1.

Derivation of the study population, beginning with the original cohort of infants from then ELGAN Study 

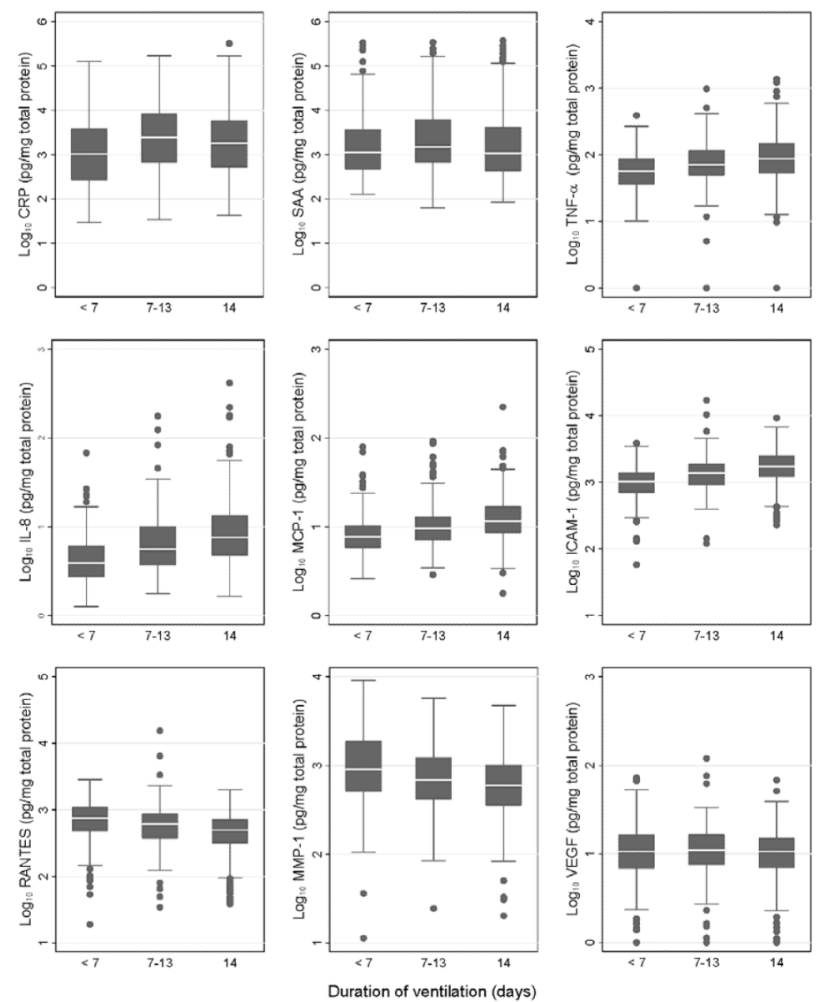

Figure 2.

Blood concentrations of 9 inflammation-associated proteins on day 14 among newborns classified by the cumulative number of days they were ventilated during the first 2 postnatal weeks. Concentrations of proteins have been log transformed for illustrative purposes. The median is the line close to the middle of each box, and the $25^{\text {th }}$ and $75^{\text {th }}$ centiles are indicated by the top and bottom of the box. The length of the vertical lines above and below the box indicates the limits of the range of values, exclusive of outliers, identified by black dots. 


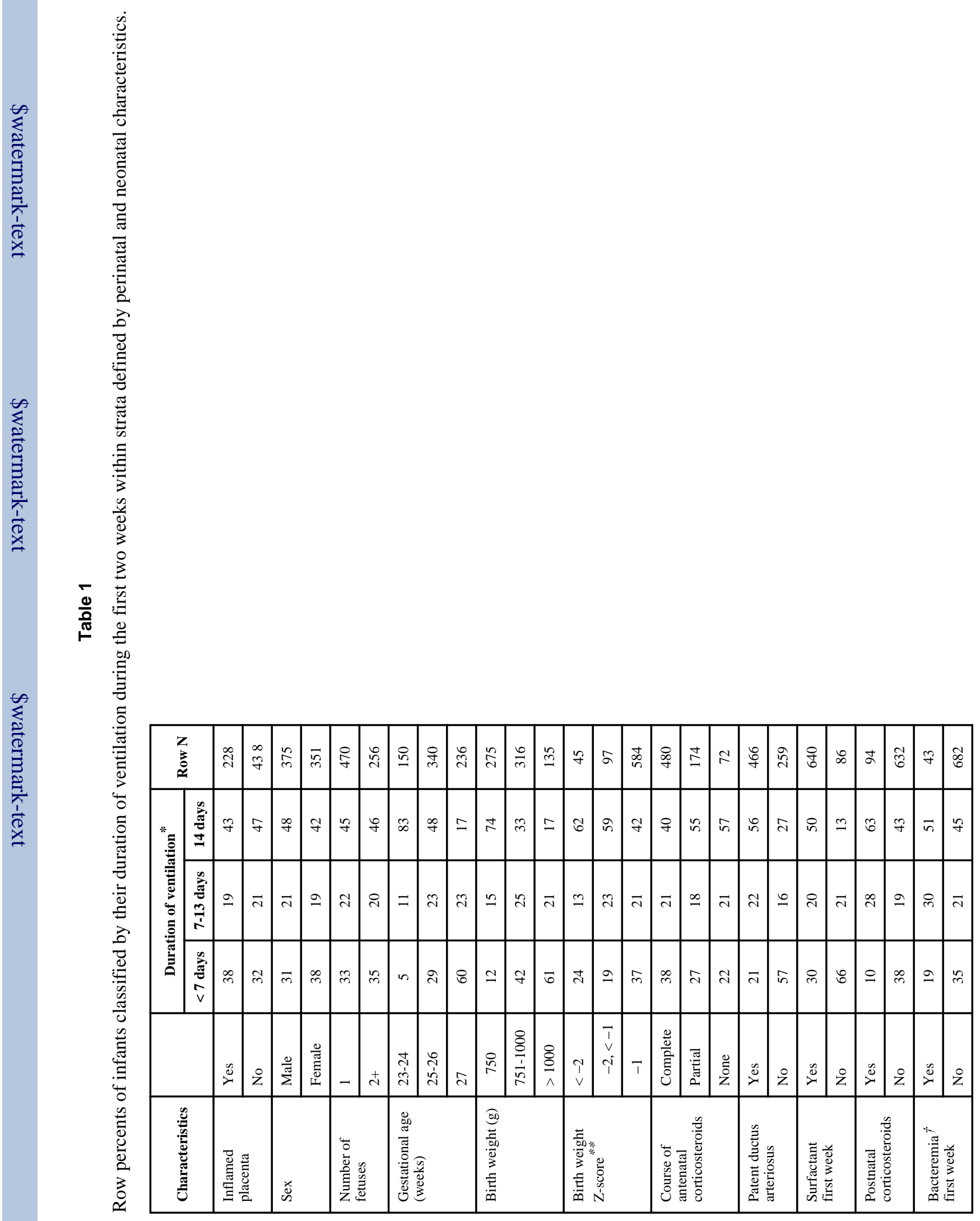




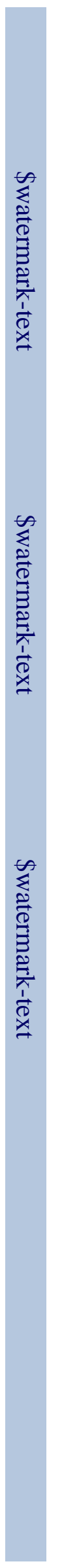

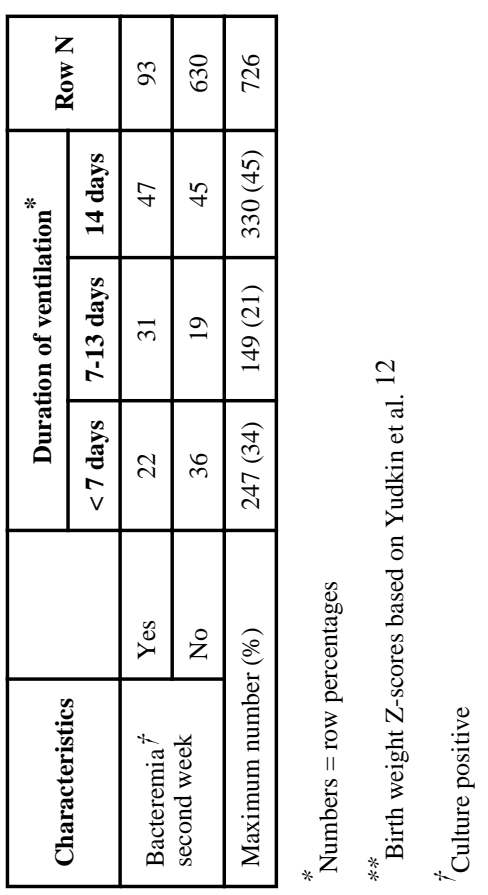


Table 2

Odds ratios (99\% confidence intervals) of a concentration in the top quartile of each protein associated with duration of ventilation after adjustment for gestational age, placental inflammation ${ }^{*}$, and antenatal corticosteroids. The two data columns on the left present the results among the entire sample $(\mathrm{N}=726)$. The two data columns on the right present the results among the newborns who did not have bacteremia during the first two postnatal weeks $(\mathrm{N}=597)$. The referent group for each set of analyses consists of infants who were ventilated less than 7 days. Statistically significantly elevated odds ratios are bolded, whereas as statistically significantly reduced odds ratios are bolded and italicized.

\begin{tabular}{|c|c|c|c|c|}
\hline \multirow{2}{*}{ Protein } & \multicolumn{2}{|c|}{ Total sample } & \multicolumn{2}{|c|}{ Bacteremia-free sample } \\
\hline & Vent 7-13 days & Vent 14 days & Vent 7-13 days & Vent 14 days \\
\hline \multicolumn{5}{|c|}{ INDICATORS OF SYSTEMIC INFLAMMATION } \\
\hline CRP & $2.1(1.1,4.0)$ & $1.5(0.8,2.8)$ & $1.8(0.9,4.0)$ & $1.6(0.8,3.1)$ \\
\hline SAA & $1.9(1.03,3.6)$ & $1.6(0.9,2.9)$ & $2.4(1.1,4.9)$ & $1.5(0.8,3.0)$ \\
\hline MPO & $1.4(0.8,2.7)$ & $1.7(0.9,3.0)$ & $1.5(0.7,3.1)$ & $1.9(0.97,3.5)$ \\
\hline \multicolumn{5}{|c|}{ CYTOKINES AND RECEPTORS } \\
\hline $\mathrm{IL}-1 \beta$ & $1.6(0.8,3.0)$ & $1.9(1.03,3.4)$ & $1.4(0.7,3.0)$ & $1.9(1.0,3.6)$ \\
\hline IL-6 & $1.5(0.8,2.9)$ & $1.8(1.01,3.4)$ & $1.3(0.6,2.8)$ & $2.0(1.01,3.8)$ \\
\hline IL-6R & $0.9(0.5,1.7)$ & $1.0(0.6,1.9)$ & $1.1(0.5,2.2)$ & $1.1(0.6,2.1)$ \\
\hline TNF- $a$ & $2.0(1.02,3.9)$ & $2.7(1.5,5.1)$ & $1.9(0.9,4.0)$ & $2.9(1.4,5.6)$ \\
\hline TNF-R1 & $1.5(0.7,2.9)$ & $2.8(1.5,5.3)$ & $1.3(0.6,3.0)$ & $2.8(1.5,5.6)$ \\
\hline TNF-R2 & $1.2(0.6,2.2)$ & $1.5(0.8,2.8)$ & $0.7(0.3,1.7)$ & $1.4(0.7,2.7)$ \\
\hline \multicolumn{5}{|l|}{ CHEMOKINES } \\
\hline IL-8 (CXCL8) & $2.6(1.3,5.2)$ & $3.5(1.8,6.6)$ & $2.4(1.1,5.2)$ & $3.5(1.7,7.0)$ \\
\hline MCP-1 (CCL2) & $2.0(0.97,4.0)$ & $4.5(2.3,8.6)$ & $1.9(0.9,4.3)$ & $4.0(2.0,8.0)$ \\
\hline MCP-4 (CCL13) & $0.7(0.4,1.4)$ & $0.7(0.4,1.3)$ & $0.8(0.4,1.6)$ & $0.8(0.4,1.4)$ \\
\hline MIP-1 $\beta$ (CCL4) & $0.9(0.5,1.7)$ & $0.5(0.3,0.9)$ & $0.9(0.5,1.8)$ & $0.4(0.2,0.8)$ \\
\hline RANTES (CCL5) & $0.5(0.3,0.9)$ & $0.2(0.1,0.4)$ & $0.5(0.3,1.05)$ & $0.2(0.1,0.4)$ \\
\hline I-TAC ( CXCL11) & $0.6(0.3,1.2)$ & $0.5(0.3,0.9)$ & $0.7(0.4,1.5)$ & $0.5(0.3,1.0)$ \\
\hline \multicolumn{5}{|l|}{ ADHESION MOLECULES } \\
\hline ICAM-1 (CD54) & $3.7(1.7,7.8)$ & $8.0(3.9,17)$ & $3.0(1.2,7.6)$ & $10(4.5,24)$ \\
\hline ICAM-3 (CD50) & $1.0(0.5,1.9)$ & $0.9(0.5,1.6)$ & $1.1(0.6,2.3)$ & $1.1(0.6,2.0)$ \\
\hline VCAM-1 (CD106) & $1.0(0.5,1.8)$ & $0.9(0.5,1.6)$ & $0.8(0.4,1.7)$ & $0.9(0.5,1.6)$ \\
\hline E-SEL (CD62E) & $1.3(0.7,2.5)$ & $1.8(0.97,3.2)$ & $1.3(0.6,2.8)$ & $2.0(1.04,3.8)$ \\
\hline \multicolumn{5}{|c|}{ MATRIX METALLOPROTEINASES } \\
\hline MMP-1 & $0.6(0.3,1.1)$ & $0.3(0.2,0.6)$ & $0.6(0.3,1.3)$ & $0.4(0.2,0.7)$ \\
\hline MMP-9 & $2.1(1.1,3.9)$ & $1.9(1.02,3.5)$ & $2.1(0.99,4.3)$ & $2.1(1.1,4.0)$ \\
\hline \multicolumn{5}{|l|}{ ANGIOGENIC PROTEINS } \\
\hline VEGF & $0.9(0.5,1.7)$ & $0.5(0.3,0.9)$ & $1.0(0.5,2.0)$ & $0.5(0.3,1.03)$ \\
\hline VEGF-R1 & $1.4(0.7,2.6)$ & $1.2(0.7,2.2)$ & $1.5(0.7,3.0)$ & $1.2(0.6,2.2)$ \\
\hline VEGF-R2 & $1.4(0.8,2.6)$ & $0.8(0.5,1.5)$ & $1.2(0.6,2.5)$ & $0.7(0.4,1.5)$ \\
\hline IGFBP-1 & $0.8(0.4,, 1.5)$ & $0.9(0.5,1.7)$ & $0.7(0.3,1.4)$ & $0.9(0.5,1.8)$ \\
\hline
\end{tabular}


Inflammation: grade 3 and stage 3 chorionic plate inflammation, or grade 3 external membrane inflammation, or grade 3 or higher umbilical cord inflammation, or neutrophilic infiltration into fetal stem vessels in the chorionic plate 